\title{
Area of Bubble Influence due to Sliding Bubbles in Subcooled Boiling Flow
}

Junsoo Yoo, Carlos E. Estrada-Perez, Yassin A. Hassan

October 2018

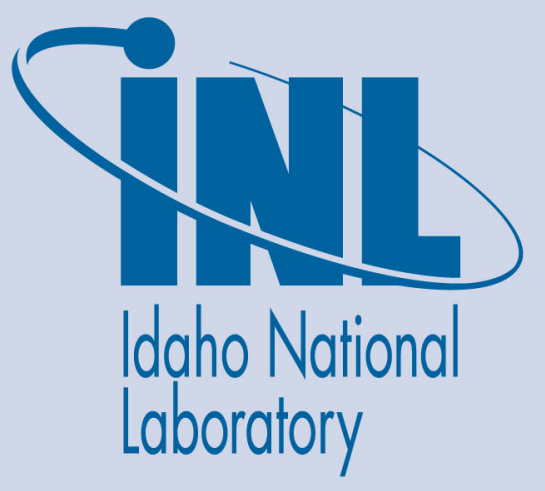

The INL is a U.S. Department of Energy National Laboratory operated by Battelle Energy Alliance 


\title{
Area of Bubble Influence due to Sliding Bubbles in Subcooled Boiling Flow
}

\author{
Junsoo Yoo, Carlos E. Estrada-Perez, Yassin A. Hassan
}

October 2018

Idaho National Laboratory Idaho Falls, Idaho 83415

http://www.inl.gov

Prepared for the

U.S. Department of Energy

Under DOE Idaho Operations Office

Contract DE-AC07-05ID14517 


\title{
Area of Bubble Influence due to Sliding Bubbles in Subcooled Boiling Flow
}

\author{
Junsoo Yoo $^{\mathrm{a}, *}$, Carlos E. Estrada-Perez ${ }^{\mathrm{b}}$, Yassin A. Hassan ${ }^{\mathrm{b}}$ \\ ${ }^{a}$ Idaho National Laboratory, 2525 North Fremont Ave., P.O.Box 3860, Idaho Falls, ID 83415-3870, USA \\ ${ }^{b}$ Texas A\&M University, Department of Nuclear Engineering, 3133 TAMU, College Station, TX 77843-3133, USA
}

\begin{abstract}
The heat transfer effect of sliding bubbles is discussed in two aspects based on new experimental findings: (i) the area of bubble influence and (ii) bubble sliding characteristics influencing the degree of wall heat transfer. One notable finding was that the bubble sliding behavior, characterized by sliding trajectories, played a crucial role in determining the area of bubble influence and the bubble influence factor $(K)$. Also, such sliding characteristic was observed strongly dependent on the sliding bubble size. An empirical model has been proposed based on this finding to evaluate the bubble influence factor $(K)$ for the sliding bubbles. Another experimental finding was that the bubble sliding characteristic, represented by bubble spreading factor $(S)$, had a significant impact on the degree of wall heat transfer induced by sliding bubbles. This is due to the fact that the bubbles spread across the heater width as they slid downstream, which reduced the effective frequency of sliding bubbles per unit wall area. These new findings not only improve our understanding of the heat transfer associated with sliding bubbles, but also are expected to contribute to improving the insight in the existing CFD boiling heat transfer models.
\end{abstract}

Key words: Sliding bubble, area of bubble influence, bubble sliding trajectory, subcooled boiling flow

\footnotetext{
* Corresponding author: Tel. +1 208-526-2024; Email address: junsoo.yoo@inl.gov; kaks2000@gmail.com (J. Yoo)
} 


\section{Nomenclature}

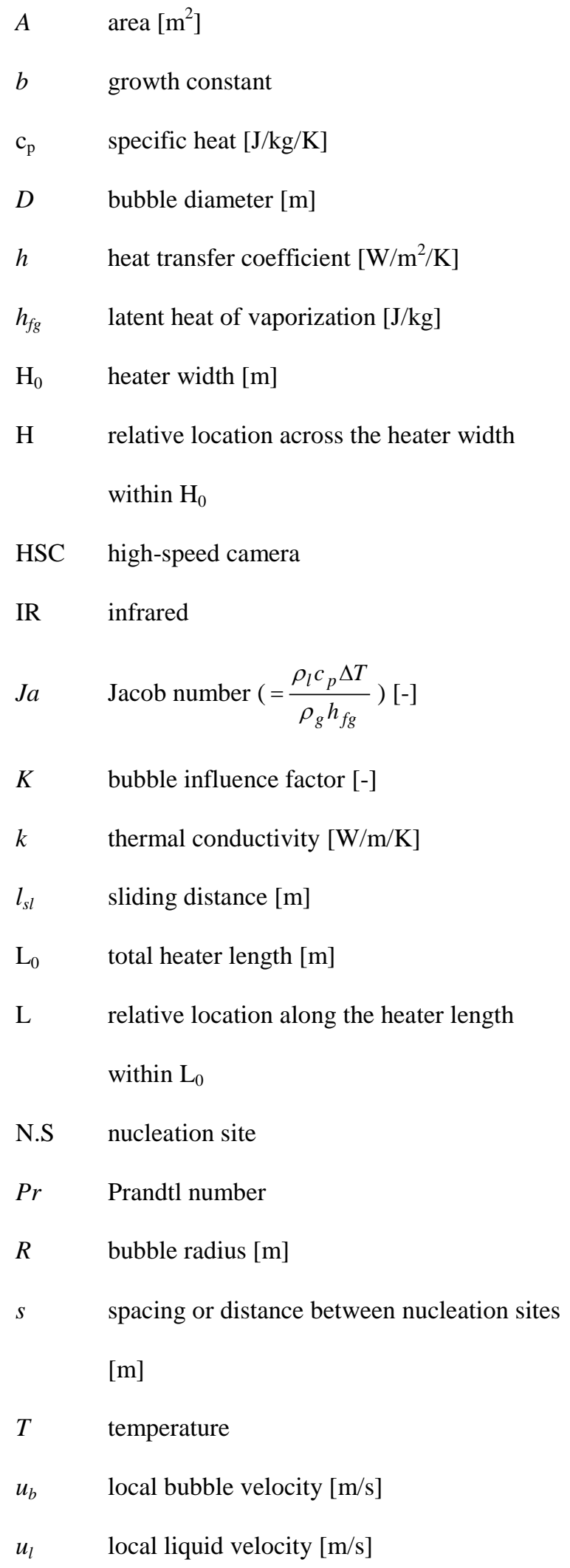

$u_{l, b u l k} \quad$ bulk liquid velocity $[\mathrm{m} / \mathrm{s}]$

\section{Greeks}

$\rho \quad$ density $\left[\mathrm{kg} / \mathrm{m}^{3}\right]$

$\sigma \quad$ surface tension $[\mathrm{N} / \mathrm{m}]$

$\alpha \quad$ thermal diffusivity $\left[\mathrm{m}^{2} / \mathrm{s}\right]$

\section{Subscript}

b bubble

g gas

$i \quad$ interface

$l \quad$ liquid

sat saturated

$s l \quad$ sliding 


\section{Introduction}

After first observed by Gunther as early as 1950s [1], the sliding bubble has received a great deal of attention due to its significant impact on wall heat transfer. Many experimental boiling studies have proven the significance of bubble sliding in terms of heat transfer improvement [2-4]. The authors' recent work also clearly demonstrated that, as can be seen in Fig. 1, the drastic improvement of wall heat transfer due to the sliding bubbles emanating from a "single" nucleation site. This strongly implies that the bubble sliding impact on wall heat transfer can become as important as the bubble nucleation.

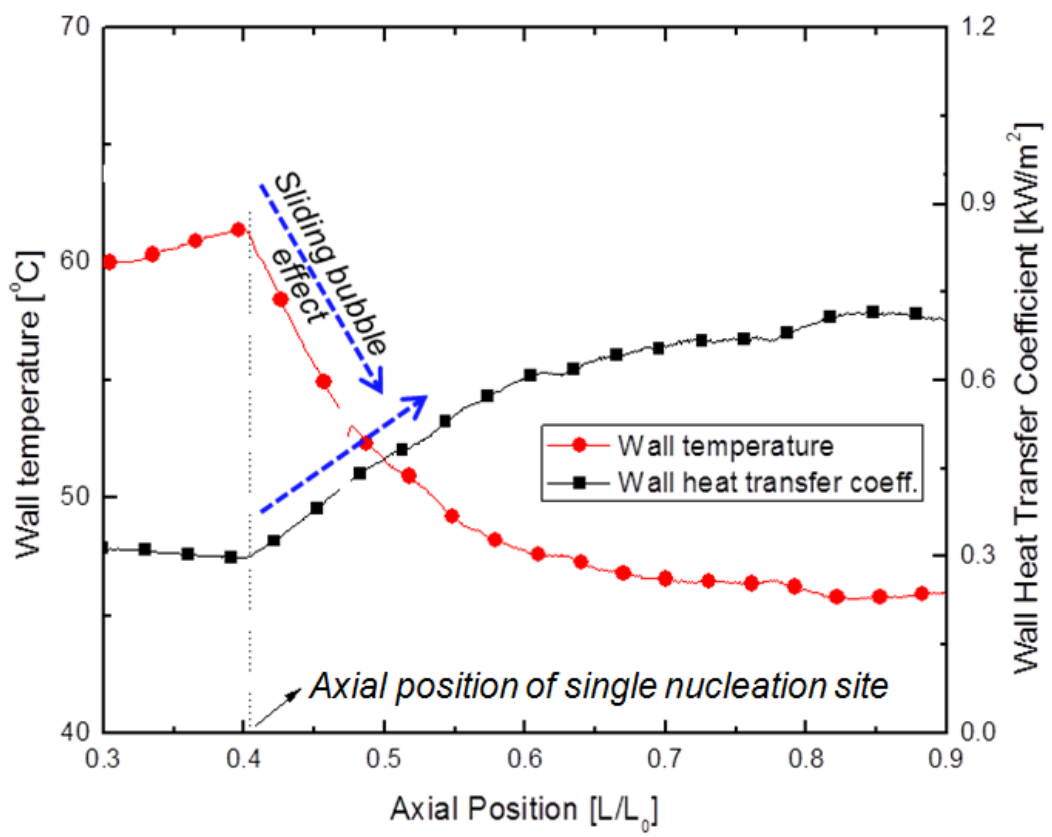

Fig. 1. A typical observation of Yoo et al. (2016) for the wall heat transfer enhancement by sliding bubbles

$$
\left(\mathrm{q}_{\mathrm{w}}=9.5 \mathrm{~kW} / \mathrm{m}^{2}, \Delta \mathrm{T}_{\mathrm{sub}, \mathrm{i}}=4.5^{\circ} \mathrm{C}, \mathrm{G}=140 \mathrm{~kg} / \mathrm{m}^{2} / \mathrm{s}\right)
$$

In this regard, effort has naturally been increased in CFD boiling research to properly address the heat transfer effect of sliding bubbles in subcooled boiling flows [5-7]. From a physical standpoint, two mechanisms are mainly involved in the sliding bubble-induced heat transfer: (i) evaporation and (ii) transient conduction.

Evaporation occurs when the heat of the wall is passed through a thin liquid film between the wall and the sliding bubble, which causes the sliding bubbles to grow. Meanwhile, the sliding bubbles repeatedly disrupt the thermal boundary layer above the heated wall, during which considerable heat from the wall can be removed from the wall 
(transient conduction). In CFD boiling analysis, several physical parameters, so-called "sliding bubble parameters", are used to model the sliding bubble-induced heat transfer. The sliding bubble parameters typically used for CFD boiling analysis include sliding bubble size (or growth), bubble sliding distance, bubble sliding velocity, and area of bubble influence, etc. Table 1 summarizes the modeling approaches taken by the existing CFD boiling studies for the sliding bubble parameters.

Table 1. Modeling of fundamental sliding bubble parameters in CFD boiling studies

\begin{tabular}{|c|c|c|c|c|c|}
\hline & $\begin{array}{l}\text { Bubble growth } \\
\text { during sliding } \\
\text { (evaporation) }\end{array}$ & $\begin{array}{l}\text { Sliding bubble } \\
\text { coalescence }\end{array}$ & $\begin{array}{l}\text { Bubble sliding } \\
\text { velocity }\end{array}$ & $\begin{array}{c}\text { Area of bubble } \\
\text { influence (or bubble } \\
\text { influence factor) }\end{array}$ & Sliding distance \\
\hline $\begin{array}{l}\text { Kurul and } \\
\text { Podowski [8] }\end{array}$ & - & - & - & $\begin{array}{l}\text { Delvalle and Kenning } \\
\text { [9] (see Eq. (1) and } \\
\text { Table } 2 \text { below) }\end{array}$ & - \\
\hline Basu et al. [5] & Basu et al. [5] ${ }^{(1)}$ & Reduction factor & $u_{b}=C_{v} t_{s l}^{0.5}$ & $A_{s l}=\mathrm{C} \cdot D_{s l} l l^{(8)}$ & $l_{s l}=\frac{2}{3} C_{v} t_{s l}^{1.5}$ \\
\hline Yeoh et al. [6] & $\underset{(2)}{\text { Zuber }[10], b=0.21}$ & Reduction factor & $u_{b}=C_{v} t_{s l}^{0.5}$ & $\begin{array}{l}\text { Judd and Hwang [11] } \\
\text { (see Eq. (1) and Table } \\
2 \text { below) }\end{array}$ & $l_{s l}=\frac{2}{3} C_{v} t_{s l}^{1.5}$ \\
\hline Bae et al. [12] & $\operatorname{l}_{(2)}^{\text {Zuber }[10], b=1.73}$ & $\begin{array}{l}\text { Reduction factor } \\
\text { (4) }\end{array}$ & $u_{b}=0.5 u_{l}{ }^{(6)}$ & ( & $\begin{array}{l}\text { Force balance } \\
\text { model }\end{array}$ \\
\hline Yun et al. [13] & $\begin{array}{l}\text { Yun et al. }[13] \\
b=1.56^{(3)}\end{array}$ & - & $u_{b}=u_{l}$ & $\begin{array}{l}\text { Delvalle and Kenning } \\
\text { [9] (see Eq. (1) and } \\
\text { Table } 2 \text { below) }\end{array}$ & $\begin{array}{l}\text { Force balance } \\
\text { model }\end{array}$ \\
\hline Gilman [7] & Basu et al. [5] ${ }^{(1)}$ & $\begin{array}{l}\text { Reduction factor } \\
\text { (4) }\end{array}$ & $u_{b}=u_{l}^{(7)}$ & $A_{s l}=D_{s l} l_{s l}$ & $l_{s l}=N_{\text {merged }} \cdot s+l_{s l}^{\prime}{ }^{\prime 9)}$ \\
\hline
\end{tabular}

(1) $\frac{D_{s l}^{2}-D_{0}^{2}}{t_{s l} \alpha_{l} J a_{\text {sup }}}=\frac{1}{15\left(0.015+0.0023 \operatorname{Re}_{D}^{0.5}\right)\left(0.04+0.023 J a_{\text {sub }}^{0.5}\right)}$

(where $D_{0}$ is the initial sliding diameter, $R e_{D}$ is the Reynolds number based on bubble diameter). This empirical correlation was derived based on the Maity [14] for a sliding bubble on a vertical surface.

(2) $R(t)=\frac{2 b}{\sqrt{\pi}} J a \sqrt{\alpha_{l} t}$ (where $b$ is an empirical constant).

(3) $R(t)=\frac{2 b}{\sqrt{\pi}} J a \sqrt{\alpha_{l} t}-\frac{b q_{i}^{\prime \prime}}{s h_{f g} \rho_{g}} t\left(\right.$ where $b=1.56, s=2, q_{i}=h_{i}\left(T_{s a t}-T_{l}\right), h_{i}=k_{l} / D_{\mathrm{b}}\left(2+0.6 \operatorname{Re}_{D}^{0.5} \operatorname{Pr}^{0.3}\right)$

(4) Reduction factor is defined by considering the sliding distance $\left(l_{s l}\right)$ and the spacing between nucleation sites $(s)$ [5].

${ }^{(5)}$ This was first proposed by Basu et al. [5]. $C_{v}$ is an acceleration coefficient defined as $C_{v}=3.2 u_{l, b u l k}+1$.

(6) This relation was first proposed by Situ et al. [15] and, Bae et al. [12] apply it to estimate the shear-lift force.

(7) Gilman [7] assumed this relation to determine the bubble sliding time $\left(t_{s l}=l_{s l} / u_{b}\right)$ and subsequently to calculate the growth of sliding bubble. Gilman [7] evaluated the shear-lift force based on the velocity difference between the bubble adjacent to the wall $\left(u_{b}=u_{l}\right)$ and bulk liquid $\left(u_{l, b u l k}\right)$.

${ }^{(8)} A_{s l}$ is the sliding area swept by sliding bubble, where $C$ denotes the ratio of bubble base to the average sliding bubble diameter. $C$ was given by a correlation derived based on the Maity [14] [i.e., $C=1-\exp \left(-2 \varphi^{0.6}\right), \varphi$ is the static contact angle in degrees]. 
${ }^{(9)} N_{\text {merged }}$ denotes the number of bubble coalescence during sliding, $s$ is the spacing between nucleation sites, $l_{s l}$ ' is the sliding distance travelled from the last event of coalescence to lift-off.

Table 1 shows that the modeling of sliding bubble parameters still highly rely on simplifying assumptions, empirical constants, and empirical models developed originally for non-sliding bubbles. In addition, the individual models and assumptions shown in Table 1 have rarely been validated against experimental data. From the experimental standpoint, this is because the sliding bubble parameters are often very difficult to measure through visualization due to the high complexity and random nature of the boiling phenomenon. Therefore, a special effort based on bottom-up approach is required to gain a deeper insight into those fundamental parameters from boiling experiments. For instance, controlling the randomness of boiling phenomenon to enhance the bubble image quality would be of great help. In this context, Yoo et al. recently performed a flow boiling experiment while keeping a "single" active nucleation site under various subcooled flow boiling conditions [16, 17]. In this experiment, the phenomenological complexity induced by the vapor bubbles was minimized, which subsequently allowed clearer observation of the sliding bubble dynamics and their effect on wall heat transfer.

Of many sliding bubble parameters, this paper focuses on the (i) area of bubble influence and (ii) wall heat transfer improvement in the presence of sliding bubbles. This study was motivated by the experimental work of Yoo et al. $(2016)[16,17]$. The main objective is to identify the knowledge gap between the experimental observations/findings and the insight in the existing CFD boiling models.

The area of bubble influence is an important factor that must be well characterized for the wall heat partitioning model $[6,8]$ that has been widely adopted for the CFD boiling researches. In the CFD boiling analysis, the area of bubble influence is usually defined as follows:

$$
\begin{aligned}
& A_{i}=K \frac{\pi D_{d}^{2}}{4} \quad \text { for a departure bubble (non-sliding) } \\
& A_{i}=K l_{s l} D_{s l} \quad \text { for a sliding bubble }
\end{aligned}
$$

where $A_{i}$ is the area of bubble influence, $K$ is the bubble influence factor, $D_{d}$ is the departure diameter, $l_{s l}$ is the sliding distance, and $D_{s l}$ is the average sliding bubble diameter over the sliding distance $l_{s}$.

In Eqs. (1) and (2) the empirical constant $K$ is called bubble influence factor, which determines how widely the thermal influential area of bubble spreads as compared to the departure or sliding bubble diameter. Once the $K$ is 
determined, the wall heat partitioning model assumes that the heat transfer mode of transient conduction (or quenching) occurs within the area of bubble influence $\left(A_{i}\right)$ calculated by Eqs. (1) and (2).

Table 2 shows the values of $K$ available in the literature with the base experiments originally used to provide them. The $K$ values have been measured in both pool and flow boiling experiments, but most were from the pool boiling experiments with horizontal heater surfaces. Mikic and Rohsenow [18] postulated that the extent of bubble influence was twice as large as the bubble departure diameter (i.e., $K=4$ ). Within this area of bubble influence, the wall heat was assumed to be transferred to the cold liquid drawn by a departing bubble via transient conduction. Kenning et al. [19] proposed the $K$ values between 2 and 5 based on the boiling experiment in saturated pool. Judd and Hwang [11] and Collier and Thome [20] argued that the area of bubble influence was 1.8 and 2.25 times larger than the maximum bubble projected area, respectively. Han and Griffith [21] observed the hydrodynamic disturbance created by a circular particle detaching from the wall, thereby suggesting $K=4$. On the other hand, unlike previous studies, Moghaddam and Kiger [22] reported that the area of bubble influence was strictly limited to the bubble-wall contact area.

Table 2. Experimental observations for bubble influence factor $(K)$

\begin{tabular}{l|c|c|c}
\hline \multicolumn{1}{c|}{ Authors } & Base experiment & $\begin{array}{c}\text { Bubble influence } \\
\text { factor }(K)\end{array}$ & Remarks \\
\hline $\begin{array}{l}\text { Mikic and Rohsenow [18] } \\
\text { Han and Griffith [21] }\end{array}$ & Pool boiling & 4 & \\
\hline Kenning et al. [19] & Pool boiling & $2-5$ & $\begin{array}{c}\text { Considering the overlap } \\
\text { of bubble influence area }\end{array}$ \\
\hline Judd and Hwang [11] & Pool boiling & 1.8 & \\
\hline Delvalle and Kenning [9] & Flow boiling & $5.8-7.5$ & $\begin{array}{l}\text { Considering the overlap } \\
\text { of bubble influence area }\end{array}$ \\
\hline Collier and Thome [20] & Not specified & 2.25 & \\
\hline Moghaddam and Kiger [22] & Pool boiling & 0.25 & \\
\hline Kim [23] & Pool boiling & $K<<4$ & \\
\hline
\end{tabular}

In case of flow boiling, Delvalle and Kenning [9] obtained the values of $K$ between 5.8 and 7.5 in the subcooled flow boiling experiments at high wall heat flux conditions ( $75-95 \%$ of CHF). The $K$ values were obtained while matching the wall heat flux predicted by the wall heat partitioning model with their data. Delvalle 
and Kenning [9] accounted for the overlaps of the area of bubble influence. This is to prevent the area of bubble influence from increasing unacceptably in the case where many nucleation sites exist on the heater surface.

The above literature review suggests that the experimental study of $K$ based on flow boiling experiment is very scarce. Also, there is no direct observation of $K$ associated with the sliding bubbles. The bubble sliding is highly probable $[5,24]$ and has critical impact on wall heat transfer in subcooled boiling flows $[2,3,17]$. Therefore, it is important to gain the correct physical insight and apply it to the relevant boiling models. In literature, some researchers employed the same bubble influence factor $K$ for both departure and sliding bubbles [6, 12] while others took different approaches $[5,7]$ (see Table 1). However, there is no experimental evidence to determine how appropriate these modelling approaches are.

This paper discusses the new experimental findings that can improve the physical insight into the heat transfer effect of sliding bubbles in subcooled boiling flows. For this study, Yoo et al.'s experiment [16, 17] has been revisited which simultaneously and clearly observed both dynamic behaviors and thermal effects of sliding bubbles under various subcooled flow boiling conditions, and we analyzed the experimental data (image data) from a new perspective to find the new physical insight. In the following sections, the data analysis method, new experimental findings, and specific knowledge gaps that need to be filled to improve the existing CFD boiling models are described.

\section{An experimental work of Yoo et al. (2016) $[16,17]$ and image data analysis}

\subsection{Subcooled flow boiling experiment of Yoo et al. $(2016)[16,17]$}

The experimental data (image data) of Yoo et al. (2016) has been revisited and analyzed for the present study. Yoo et al. (2016) performed a subcooled flow boiling experiment with one-side heated rectangular channel as shown in Fig. 2. The working fluid was NOVEC ${ }^{\mathrm{TM}} 7000$ (3M Inc.). The fluid flew upward through a flow area of $10 \times 10 \mathrm{~mm}^{2}$. The heater wall was designed such that the heated length $\left(\mathrm{L}_{0}\right)$ and width $\left(\mathrm{H}_{0}\right)$ was $224 \mathrm{~mm}$ and $7.5 \mathrm{~mm}$, respectively. Only a single nucleation site was activated in the middle of heater wall $\left(\mathrm{L}_{\mathrm{L}} \mathrm{L}_{0} \approx 0.41\right)$ during the experiment ( $\mathrm{L}$ denotes the relative axial location from the beginning of heater within $\mathrm{L}_{0}$, i.e., $0 \leq \mathrm{L} / \mathrm{L}_{0} \leq 1$ ). This is to enhance the quality of bubble images and infrared (IR) thermal images for visual observation. As a result, the detailed observation of both bubble behaviors and their effect on wall heat transfer was achieved. During the 
experiment, three high-speed cameras (HSCs) and one IR camera were placed around the test section for bubble imaging and wall temperature thermal imaging, respectively. Specifically, HSC 1 and HSC 2 were used to observe the bubble behavior from the side of bubbles (side view) while HSC 3 captured the bubble behavior from the top of the bubbles (top view). Applying the different resolutions and observation-views to these cameras (see Fig. 2), multi-scale and multi-view observation was achieved. Also, the heat transfer effect of sliding bubbles was captured in detail using IR thermometry, the measurement accuracy of which was proved through extensive validations in our previous study [25].

The Yoo et al. experiment (2016) was conducted at atmospheric pressure within ranges of mass flux $(G)$, wall heat flux ( $\left.\mathrm{q}_{\mathrm{w}}{ }^{\prime}\right)$, and inlet subcooling $\left(\Delta \mathrm{T}_{\text {sub,in }}\right)$ of about $140-700 \mathrm{~kg} / \mathrm{m}^{2} \mathrm{~s}, 8-35 \mathrm{~kW} / \mathrm{m}^{2}$, and $4.5-13.6{ }^{\circ} \mathrm{C}$, respectively. Note that in most cases, the bubbles generated at the nucleation site tended to slide along the heater surface until exiting the test section. Accordingly, the experimental study was focused on the various sliding bubble parameters and associated thermal effects. Readers should refer to Yoo et al. $(2016)[16,17]$ for more information.

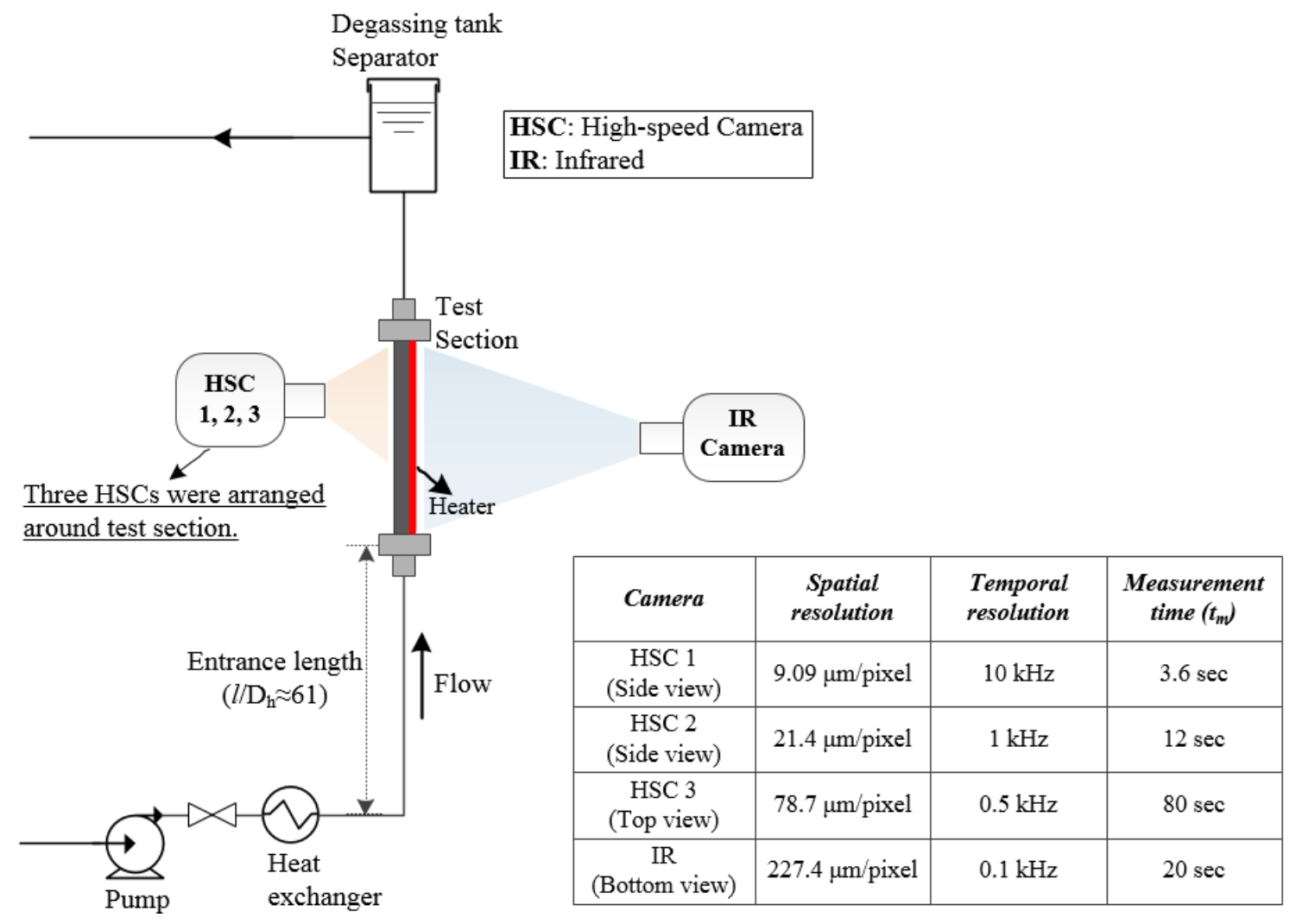

Fig. 2. A subcooled flow boiling experiment performed by Yoo et al. [16, 17] 
2.2. Image data analysis and characterization of sliding bubble parameters

In addition to achieving high image quality, special care was also made in Yoo et al. experiment $[16,17]$ to obtain reliable statistics of measured parameters via the analysis of numerous images. This process is important to avoid misleading conclusion that may arise from the random nature of boiling parameters, as discussed in our previous study [26]. In this study, the sliding bubble parameters were characterized by analyzing 36,000 and 40,000 images obtained from HSC 1 and HSC 3 respectively, and 2,000 thermal images from IR camera. The key sliding bubble parameters characterized for this study are (i) bubble size during sliding, (ii) bubble sliding trajectory, and (iii) wall area influenced by sliding bubbles (i.e., area of bubble influence).

Fig. 3 shows the representative bubble images and IR thermal image taken by Yoo et al. (2016). To characterize the bubble sliding trajectories, the bubble images taken from the top view (HSC 3) was utilized. The process of characterization is briefly summarized in Fig. 4. The characterization was first performed by converting the original bubble images to binary ones and then, generating the bubble residence fraction map. In the bubble residence fraction map, the relative fraction of bubble residence during the measurement period was presented as a value between 0 and 1 . The higher value implies that the bubbles slide through the given location on the wall more frequently during the measurement period.

Fig. 5 shows a wall temperature profile across the heater width $\left(\mathrm{H} / \mathrm{H}_{0}\right)$ typically observed by Yoo et al. (2016) $[16,17]$ ( $\mathrm{H}$ is the relative location across the heater width within $\mathrm{H}_{0}$. i.e., $0 \leq \mathrm{H} / \mathrm{H}_{0} \leq 1$ ). In the single-phase region upstream of the nucleation site at $\mathrm{L} / \mathrm{L}_{0}=0.40$, the wall temperature profile showed parabolic shape due to the thermal conduction at both edges of heater. The wall temperature profile was then significantly distorted downstream of the nucleation site at $\mathrm{L} / \mathrm{L}_{0}=0.43$ and 0.81 . This is due to the effect of sliding bubbles. In the experiment, the local distortion of the wall temperature profile was clearly observed around the path of sliding bubbles, indicating the heat transfer effect of the sliding bubbles. Fig. 5 also shows that at the region closer to the nucleation site (i.e., $\mathrm{L} / \mathrm{L}_{0}=0.43$ ) the wall temperature profile was distorted within relatively restricted area while the temperature profile became flatter at the downstream region (i.e., $\mathrm{L} / \mathrm{L}_{0}=0.81$ ). This is because the sliding bubbles slid through a narrow path during the initial sliding phase (i.e., just after departing from the nucleation site), whereas 
the bubbles spread widely across the heater width as they slid downstream. More details about this observation will be discussed in Section 3.

As noted before, the wall temperature distribution at each boiling test condition was characterized by analyzing 2,000 IR thermal images. To define the area of bubble influence in the presence of sliding bubbles, we first compared the characterized wall temperature profile and heat transfer coefficient under the influence of sliding bubbles with those of the single-phase flow region. Then, the wall temperature gradient and inflection point (i.e., $V T_{i}$,

$\nabla^{2} T_{i}$ ) were analyzed to determine the area of bubble influence as shown in Fig. 5. (in Fig. 5, the subscript $i$ denotes $i^{\text {th }}$ pixel point from the left of heater wall across the heater width).

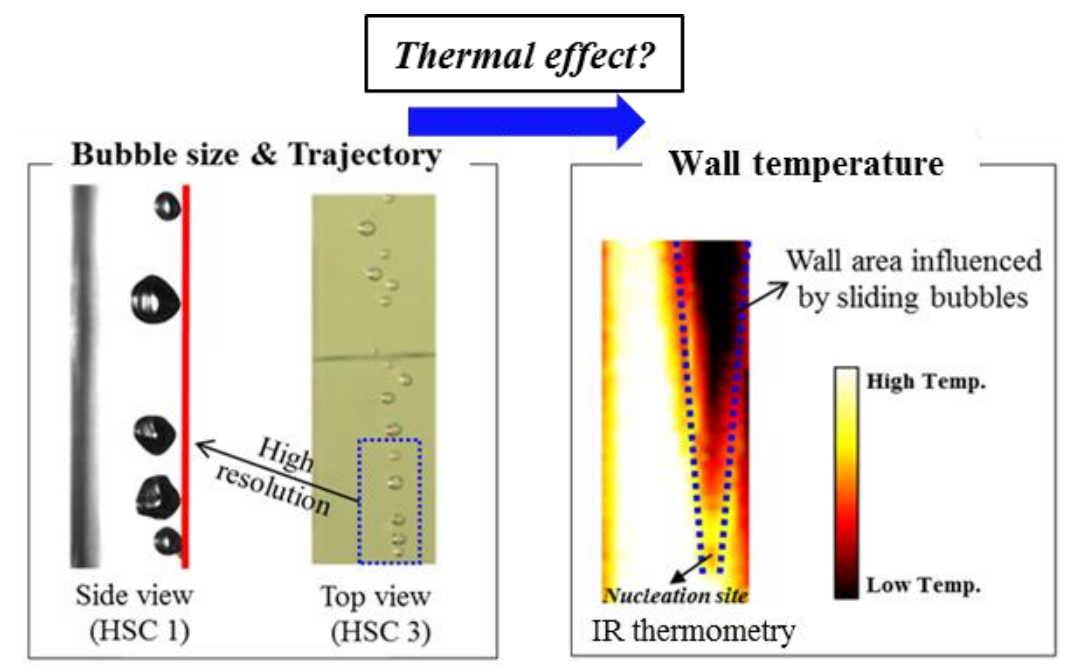

Fig. 3. Representative images taken from the high-speed cameras and IR camera 


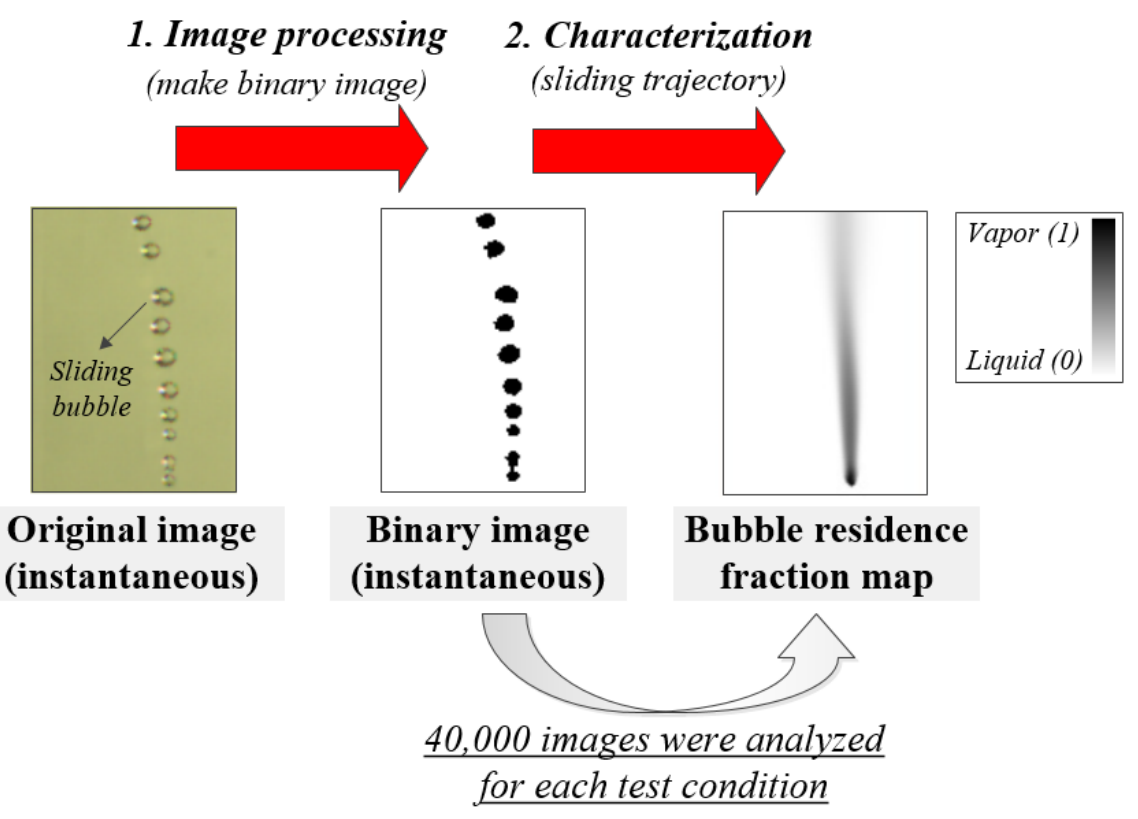

Fig. 4. Characterization of bubble sliding trajectories at a given test condition

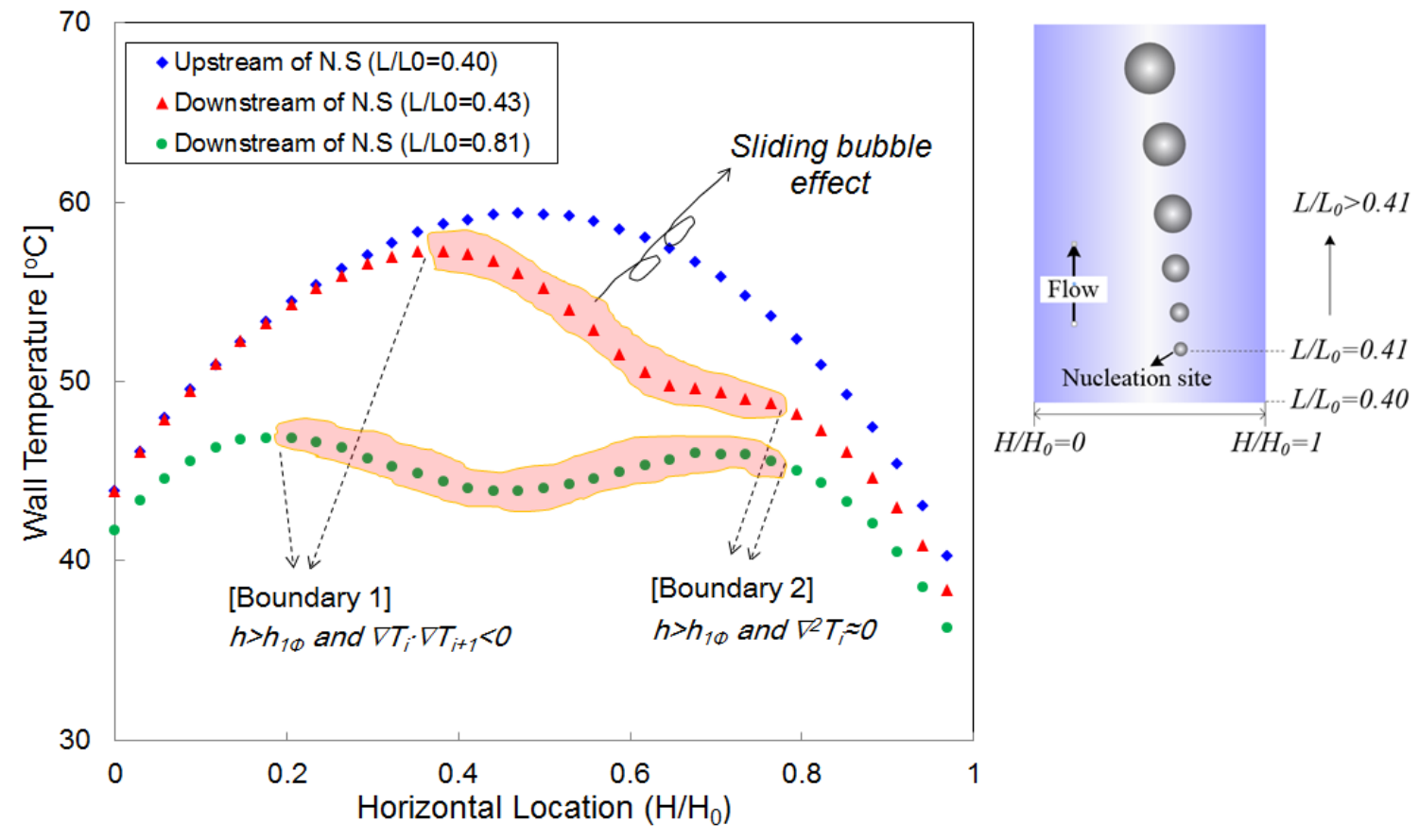

Fig. 5. Area of bubble influence determined based on IR wall temperature measurement 


\section{New experimental findings and current knowledge gaps}

\subsection{Bubble sliding trajectory and its effect on the area of bubble influence}

One important finding during the present study is that the wall area influenced by sliding bubbles significantly depends on the bubble sliding characteristics, especially the bubble sliding trajectory. The visual observation revealed that all the bubbles departing from a single nucleation site slid through various trajectories rather than following a single straight path. This results from the stochastic motion of the sliding bubbles, which is caused by the interaction between the bubbles and surrounding liquid. The specific mechanisms that are involved with the bubbles' stochastic motion include (i) turbulent characteristics of surrounding liquid, (ii) relative velocity between the bubbles and surrounding liquid, (iii) bubble growth characteristics, (iv) bubble shape deformation, etc.

This observation is in contrast to the physical assumption that has been widely taken by the existing CFD boiling models which address the heat transfer effect of sliding bubbles [5, 6]. The difference between the CFD boiling models and the current experimental finding is presented in Fig. 6. Typically, the CFD boiling models assume that the sliding bubbles always travel along a straight path, and the area of bubble influence is determined by multiplying the constant $K$ (bubble influence factor) to the sliding bubble size without considering the effect of bubble sliding trajectory. In the experiment, however, each bubble departing from the nucleation site had its own sliding path with lateral waving motions (see the right side of Fig. 6). Also, it is important to note that the characterized feature of such bubble sliding trajectory (see Fig. 4) was observed closely related to the sliding bubble $\operatorname{size}\left(D_{s l}\right)$.

To better understand the relationship between the sliding bubble size and bubble sliding trajectory, a bubble spreading factor $S$ is defined, which characterizes the total width of bubble sliding trajectories relative to the sliding bubble size during the measurement period:

$$
S=\frac{A_{s l}}{l_{s l} D_{s l}}
$$

(where $A_{s l}$ is the projected area swept by sliding bubbles, $l_{s l}$ is the sliding distance, and $D_{s l}$ is the average sliding bubble diameter within the sliding distance)

Then, for a given sliding distance $\left(l_{s l}=4.5 \mathrm{~mm}\right)$, we evaluated the bubble spreading factor $S$ based on the observations of the sliding bubbles from HSC 3 under 14 different subcooled flow boiling conditions (see Fig. 4). 
The results are shown in Fig. 7. Fig. 7 implies that the small sized sliding bubbles spread more across the heater width relative to their size $\left(D_{s l}\right)$, compared to the large sized sliding bubbles. Also, it is important to mention that this sliding characteristic represented by $S$, which depended on the sliding bubble size $\left(D_{s l}\right)$, played a critical role in determining the wall area influenced by the sliding bubbles and thus the bubble influence factor $K$. The thermal influential area due to the sliding bubbles and corresponding bubble influence factor $K$ was obtained based on the IR thermal imaging as shown in Fig. 3. The results showed that the smaller the average sliding bubble size at a given boiling test condition the wider the thermal influential area relative to their size, which means higher $K$ [see Eq. (2)]. Specifically, Fig. 8 shows that the bubble influence factor $(K)$ is a strong function of sliding bubble size $\left(D_{\text {sl }}\right)$. The varying trend of $K$ against the sliding bubble size $\left(D_{s l}\right)$ is seen to be similar to that of the bubble spreading factor $(S)$ shown in Fig. 7. This is because the bubble sliding characteristic, represented by $S$, significantly affected the area of sliding bubbles' thermal influence on the wall. In Fig. 8, the value of $K$ is shown as high as 14 for the smallest size of sliding bubbles. This value is much higher than those reported by the previous researchers (see Table 2). The flow disturbance induced by the sliding motions of the (growing) bubbles is believed to be responsible for the bubble influence factor $(K)$ that is significantly higher than the bubble spreading factor $(S)$. That is, the dynamic behavior of sliding bubbles, which is barely expected in pool boiling conditions, would have caused the greater area of thermal influence. It is also interesting to note that the ratio between the $K$ and $S$ (i.e., $K / S$ ) was kept to be around 2 (or slightly higher) for the all test cases observed in the Yoo et al. experiment.

The present study strongly implies that the existing CFD boiling models, which (i) assumes $K$ as constant or (ii) assumes the same value of $K$ in Eqs. (1) and (2), do not properly reflect the true effect of sliding bubbles. Fig. 8 also shows that the deviation between the $K$ values reported in the literature and present observation became larger as the sliding bubble size became smaller. This observation indicates that the physical distortion caused by the deficiency of existing models for $K$ may become worsened for the CFD simulation of 'high-pressure' flow boiling system because the smaller sized sliding bubbles are more likely to occur at high system pressures.

The observations shown in Figs. 7 and 8 are closely related to the fact that the smaller bubbles experienced stronger stochastic motion during sliding. This may seem contradictory to the observations of the previous researchers with air/gas bubbles rising in a stagnant liquid [27, 28]. In general, the stochastic bubble motion (e.g., rocking motion) occurs due to the interaction between the bubbles and surrounding liquid; for example, the surrounding liquid is disturbed as the bubbles move through the liquid, and the disturbed flow affects in turn the 
motion of the bubbles. In a stagnant liquid, larger air/gas bubbles usually exhibit more stochastic motions. This is because the larger bubbles are driven by stronger buoyancy force (in vertical channel) with deformable shape, thus resulting in stronger degree of flow disturbance in the surrounding liquid. In the subcooled boiling flow, however, more attention is required because the surrounding liquid moves with the bubbles and the bubbles grow during sliding. In this case, the turbulence characteristic of the flowing liquid can significantly affect the stochastic motion of the sliding bubbles. Yoo et al. (2016) observed that, as the mass flux (or velocity) of the surrounding liquid increased, the sliding bubbles became smaller and moved slower near the nucleation site. That is, the bubbles became smaller as the mass flux increased, and thus they were likely to be influenced by the stronger turbulence of the surrounding flow. This can partly explain why the bubble spreading factor $(S)$ and bubble influence factor $(K)$ increased with the decrease of bubble size in Figs. 7 and 8, but it is not enough to fully explain the mechanism. We observed that when the mass flux of the surrounding liquid was fixed, the $S$ and $K$ decreased with the increase of bubble size by increasing the heat flux or decreasing the subcooling degree. This implies that the growth behavior of sliding bubbles (e.g., inertia of bubble growth) can be another factor affecting the stochastic motion of the sliding bubbles. Thus, more investigation is required.

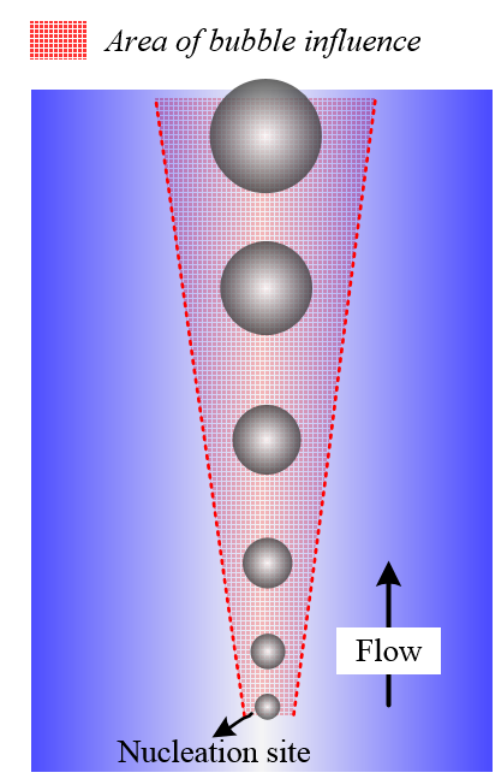

CFD boiling model to address sliding bubble effect

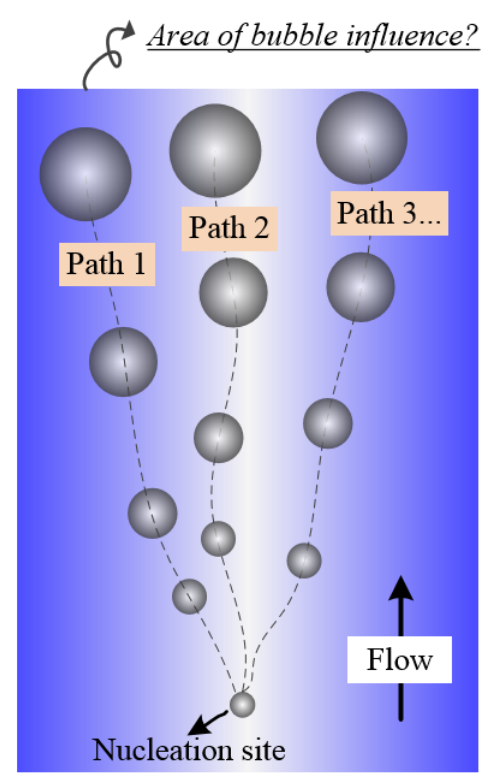

Present Observation

Fig. 6. Bubble sliding trajectory assumed in CFD boiling models (left) and experimental observation (right) 


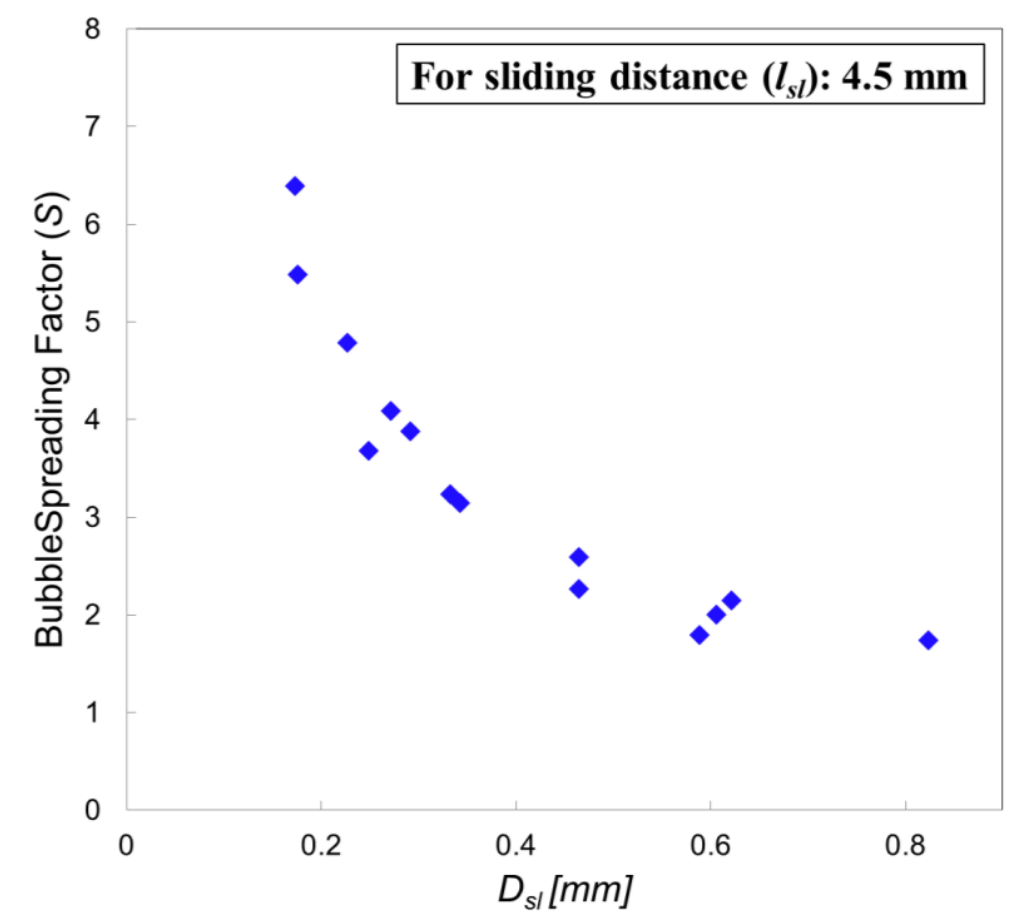

Fig. 7. Bubble spreading factor $(S)$ depending on the size of sliding bubble

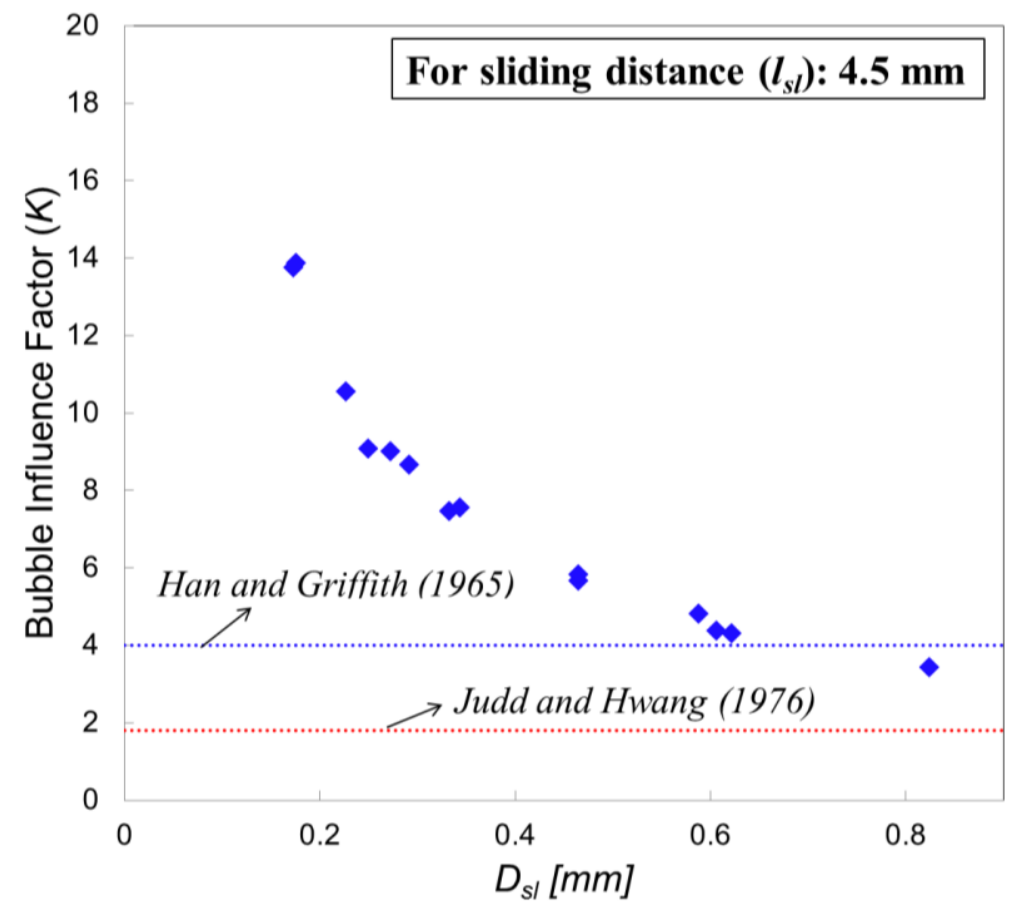

Fig. 8. Bubble influence factor $(K)$ depending on the size of sliding bubble 
Lastly, the dependency of $K$ on the size of sliding bubbles, shown in Fig. 8, was observed consistent regardless of the bubble sliding distance considered as shown in Fig. 9. Therefore, an empirical model can be proposed to estimate the bubble influence factor $K$ for the sliding bubbles as a function of Eotvos number:

$$
K=3.7+10.4 \exp (-5.9 E o)
$$

(where $E o$ is the Eotvos number defined using the average sliding bubble diameter over the sliding distance $\left(l_{s l}\right) E o=\frac{\Delta \rho g D_{s l}^{2}}{\sigma}, \Delta \rho$ is the density difference between liquid and vapor phase, $g$ is the gravitational acceleration $\left[\mathrm{kg} / \mathrm{m}^{2}\right]$ and $\sigma$ is the surface tension $\left.[\mathrm{N} / \mathrm{m}].\right)$

It is noted that Eq. (4) is proposed such that the upper and lower limit of $K$ is 14.1 and 3.7, respectively based on the present observation. Fig. 10 shows that the predictions of bubble influence factor $K$ using Eq. (4) agree well with the experimental measurements.

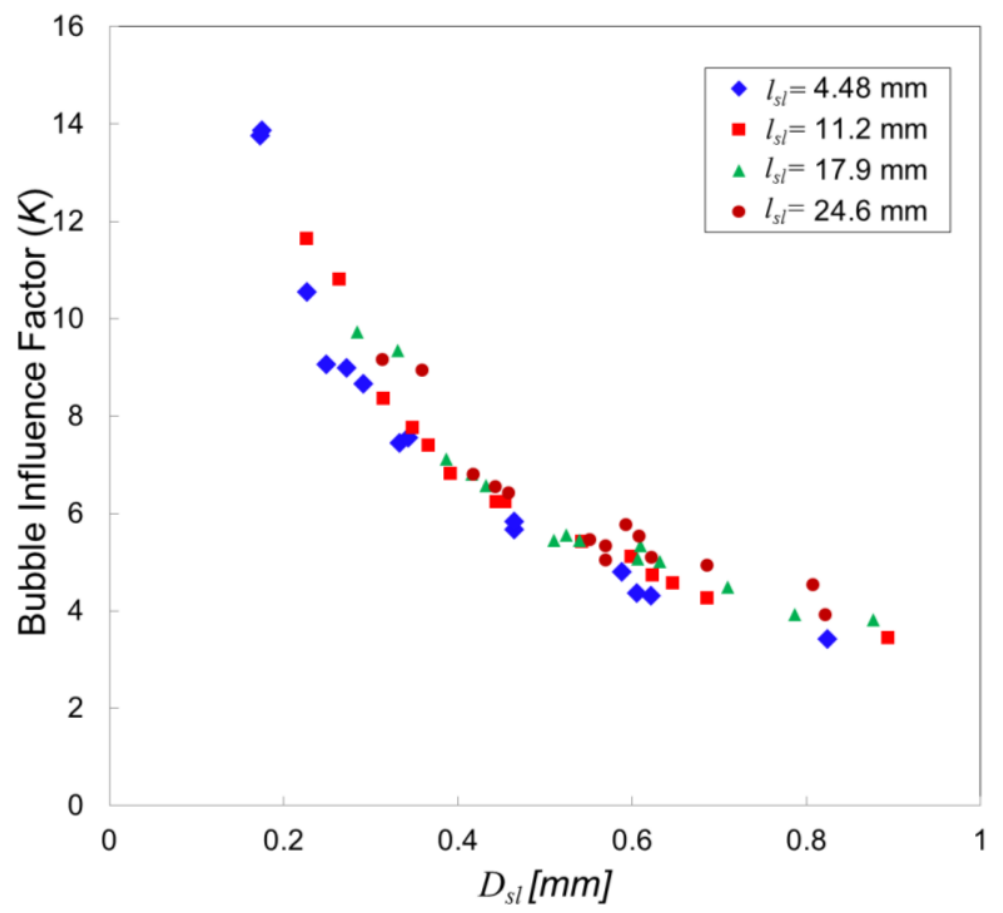

Fig. 9. Bubble influence factor $(K)$ measured with different sliding distance $l_{s l}$ 


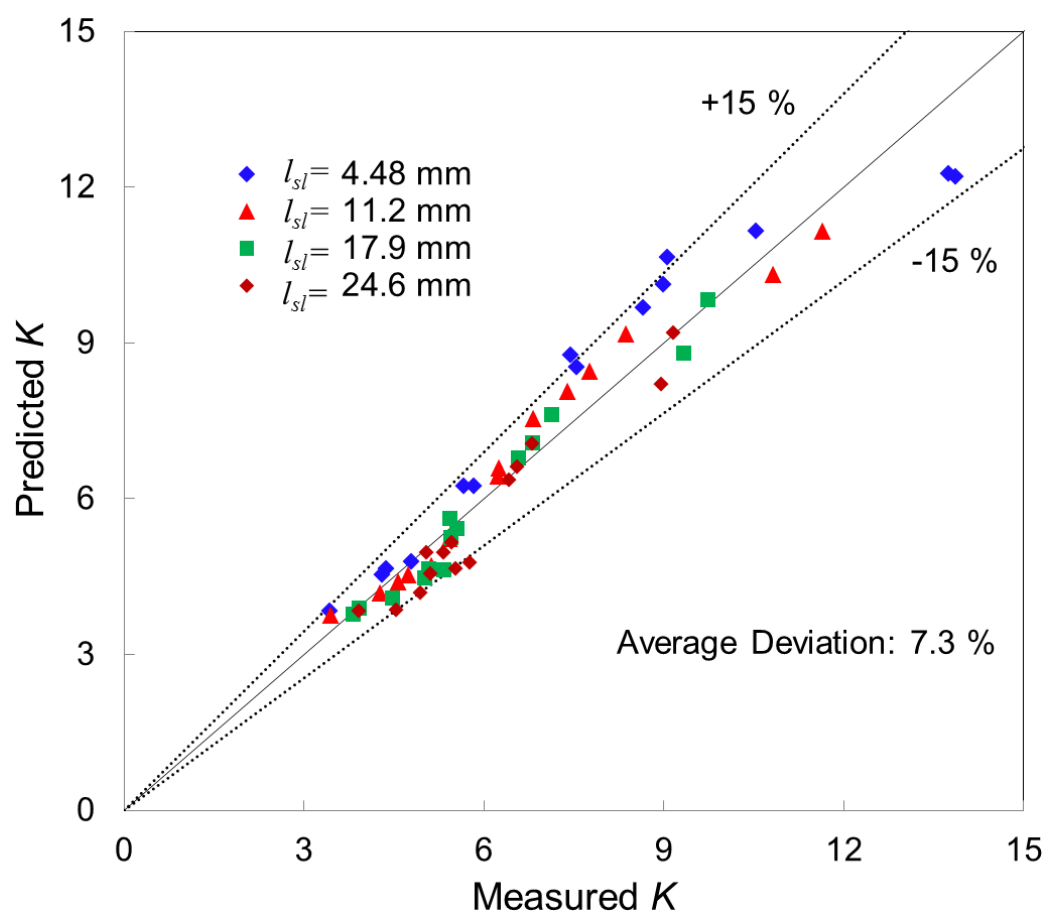

Fig. 10. Prediction of $K$ for the sliding bubbles using Eq. (4)

3.2. Influence of bubble sliding characteristic on wall heat transfer

The present study also revealed that the degree of wall heat transfer enhanced by sliding bubbles significantly depended on the bubble sliding behavior characterized by bubble spreading factor $(S)$ [Eq. (3)]. In Fig. 11, the ratio of wall heat transfer coefficients, $h_{2 \phi} / h_{1 \phi}$, measured between the single-phase (upstream of nucleation site) and two-phase (downstream of nucleation site) regions is plotted according to the variation of $S$. Note that $h_{2 \phi}$ was evaluated within the area of bubble influence $\left(A_{i}\right)$ as described in sections 2 and 3. Fig. 11 indicates that the $h_{2 \phi} h_{1 \phi}$, the degree of wall heat transfer enhancement due to the sliding bubbles, is inversely proportional to the magnitude of bubble spreading factor $(S)$. 


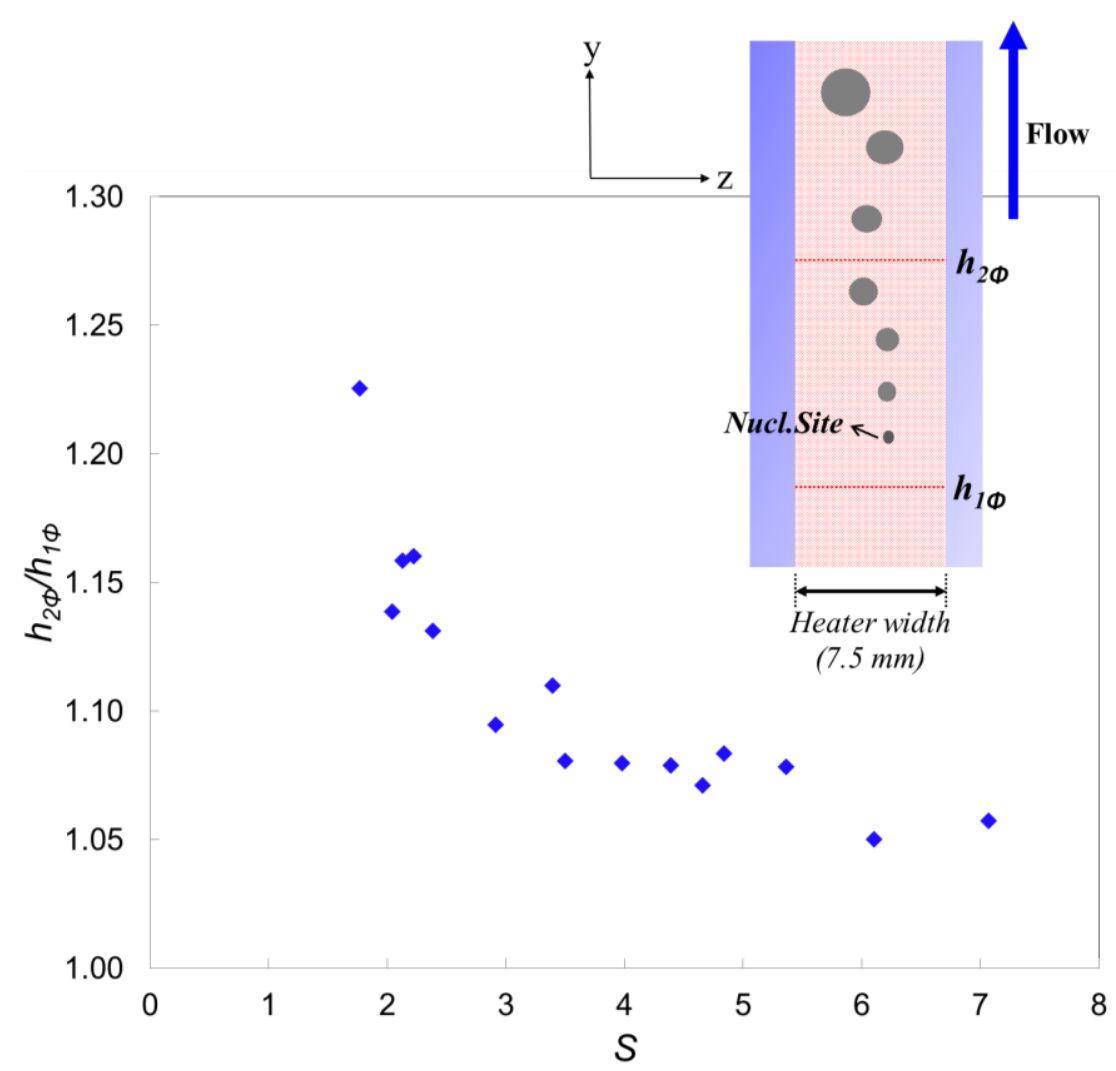

Fig. 11. Wall heat transfer enhancement induced by sliding bubbles depending on bubble spreading factor $(S)$

To gain a better insight into the underlying mechanism, we analyzed the temporal fraction of the sliding bubble residence along the heated wall during the measurement period of HSC 3 ( $80 \mathrm{sec}$, see Fig. 2). The temporal fraction of the sliding bubble residence can be characterized using the two parameters as follows:

$$
\begin{aligned}
& \overline{F_{R}}(y, z)=\int_{0}^{t_{m}} F_{R}(y, z, t) d t / \int_{0}^{t_{m}} d t \\
& \overline{F_{R}}=\int_{0}^{l_{s l}} \int_{0}^{S_{0}(y)} \overline{F_{R}}(y, z) d y d z / \int_{0}^{l_{s l}} \int_{0}^{S_{0}(y)} d y d z
\end{aligned}
$$

( $t_{m}$ is the total measurement time, $S_{0}(y)$ is the width of the area of bubble influence at axial location $y$, and $y$ is the axial direction along the upward flow as shown in Fig. 11, and $z$ is the lateral direction across the heater wall). 
In Eqs. (5) and (6), $\overline{F_{R}}(y, z)$ denotes the time-averaged local temporal fraction of the sliding bubble residence (two-dimensional in space, see Fig. 11), while $\overline{F_{R}}$ denotes the time- and area-averaged temporal fraction within the area of bubble influence. Note that $\overline{F_{R}}(y, z)$ and $\overline{F_{R}}$ are associated with the 'effective' frequency of the sliding bubbles per unit wall area. For instance, a higher value of $\overline{F_{R}}$ or $\overline{F_{R}}(y, z)$ may cause a stronger effect of transient conduction due to the frequent movement of sliding bubbles within the wall area of interest.

Fig. 12 shows the typical development of $\overline{F_{R}}(y, z)$ along the upward flow path of sliding bubbles. The sliding bubbles that just left the nucleation site tended to pass through a narrow path with a higher value of $\overline{F_{R}}(y, z)$ (for $\mathrm{L} / \mathrm{L}_{0}=0.43$ ). Thereafter, the sliding bubbles gradually spread across the heater width while travelling downstream and the value of $\overline{F_{R}}(y, z)$ decreased accordingly. We can infer from this observation that the transient conduction due to the sliding bubbles can be limited to a narrow wall area near the nucleation site, but its strength will be strong due to the high frequency of sliding bubbles. By contrast, the effect of transient conduction can extend to a larger wall area at the downstream region $\left(\mathrm{L} / \mathrm{L}_{0} \geq 0.49\right)$ but the strength will become weakened.

In Fig. 13, the dependency of $\overline{F_{R}}$ on bubble spreading factor $(S)$ is presented based on the experimental observations at 14 different subcooled flow boiling conditions. Fig. 13 shows that $\overline{F_{R}}$ decreases as the value of $S$ increases. This is because the effective sliding bubble frequency per unit wall area decreased as the sliding bubbles spread across the heater width. As a result, the effect of transient conduction within the area of bubble influence is expected to deteriorate as the value of $S$ increases. Looking back at the result shown in Fig. 11, this is one of the main reasons causing the degree of wall heat transfer enhancement $\left(h_{2 \phi} / h_{1 \phi}\right)$ to deteriorate as the value of $S$ increased. From a perspective of modeling, this also leads to a conclusion that the effect of sliding characteristic, represented by $S$, should be considered for modeling the transient conduction associated with sliding bubbles. 


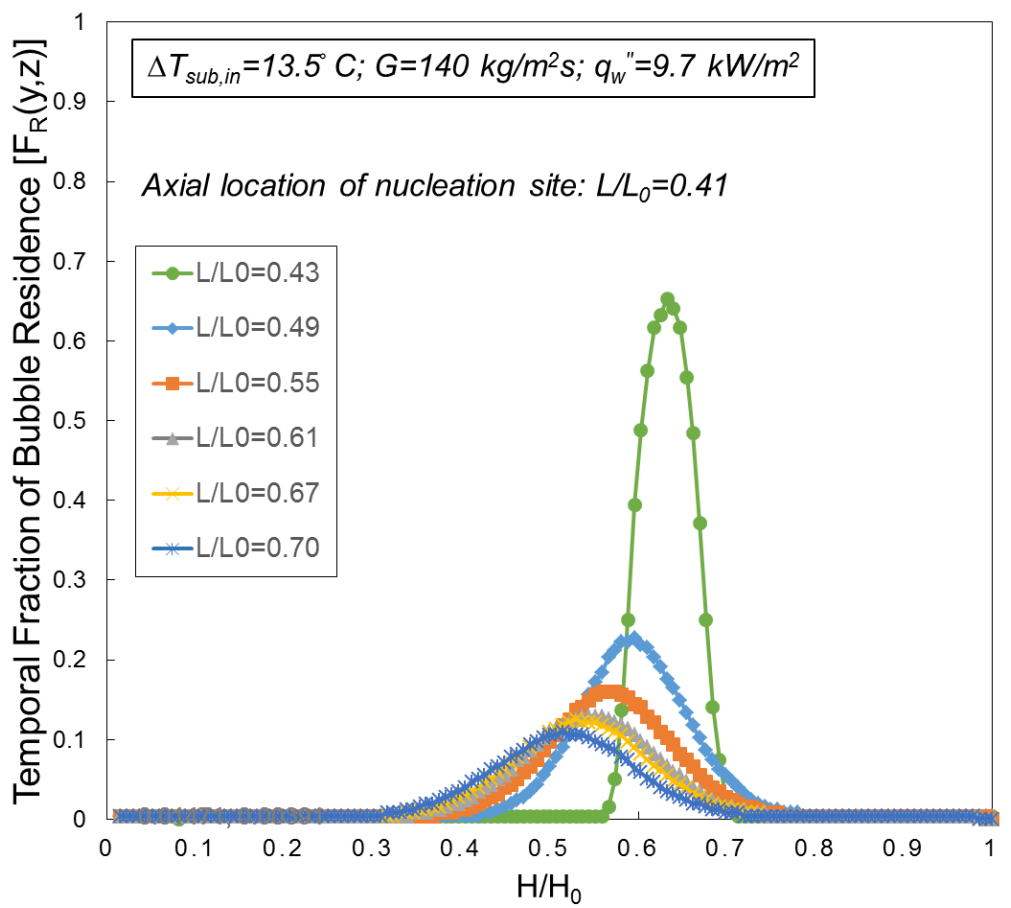

Fig. 12. A typical development of $\overline{F_{R}}(y, z)$ along the heated wall $\left(\mathrm{H}_{0}\right.$ is the total heater width $(=7.5 \mathrm{~mm})$ and $\mathrm{H}$ is the horizontal position within $\mathrm{H}_{0}$ )

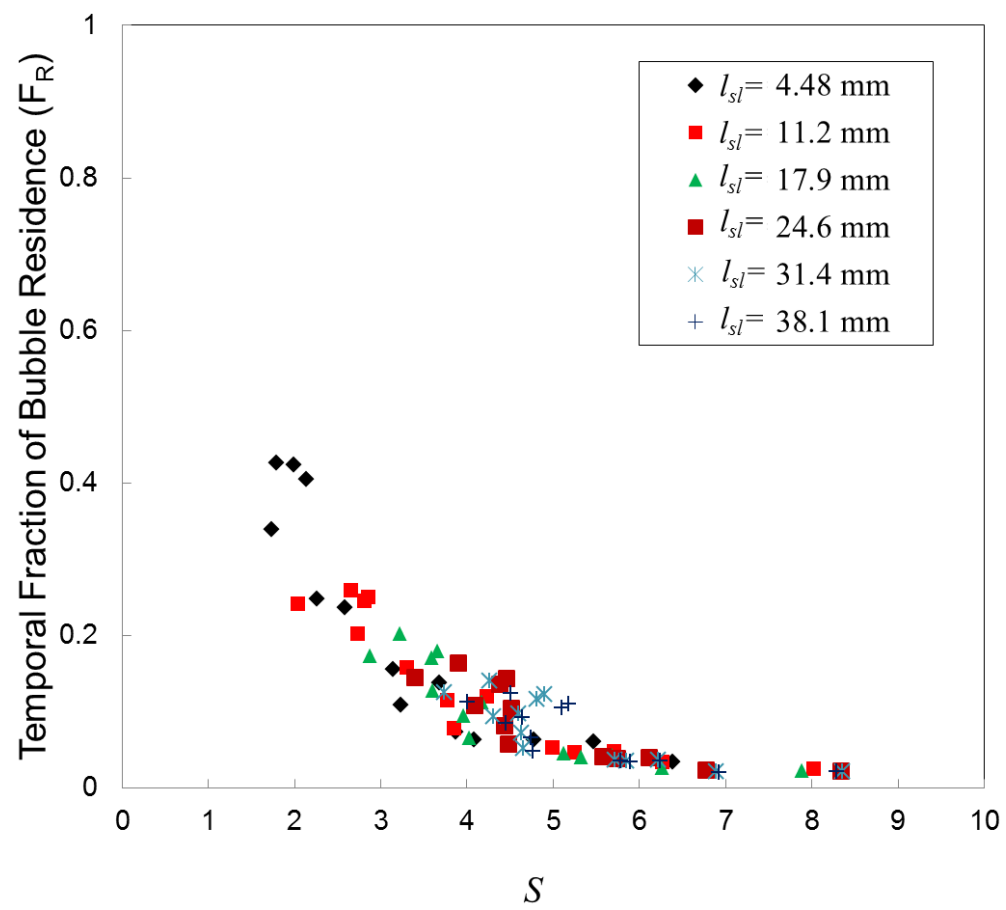

Fig. 13. Observed relation between $\overline{F_{R}}$ and $S$ 


\section{Conclusions}

This study revealed new physical insights into the heat transfer effect of sliding bubbles. One important finding is that the bubble sliding behavior, characterized by bubble sliding trajectories, plays a crucial role in determining the wall area influenced by sliding bubbles and thus bubble influence factor $(K)$. The bubble sliding characteristic was observed strongly dependent on the sliding bubble size. From this observation, an empirical model has been proposed to evaluate the bubble influence factor $(K)$. Another important finding from this study is that the degree of wall heat transfer enhanced by sliding bubbles significantly depends on the sliding characteristic represented by bubble spreading factor $(S)$. This is due to the fact that the effective frequency of the sliding bubbles per unit wall area decreases as the bubbles spread across the heater width while sliding.

The experimental insight achieved from this study helps to improve the existing CFD boiling models, particularly the model of transient conduction for the sliding bubbles. Note that the accurate prediction of the area of bubble influence associated with sliding bubbles can significantly affect the number and distribution of active nucleation sites at the downstream of flow boiling channel, two-phase flow regime, boiling curve, and thus the overall performance of the CFD boiling analysis. Moreover, the large discrepancy of bubble influence factor $(K)$ between the present observation and the values adopted in the previous CFD boiling studies strongly implies that there is much room for improvement. In particular, a special care needs to be paid to the CFD analysis of highpressure flow boiling system which is expected to involve small sized sliding bubbles.

As a future work, it would be valuable to investigate the heat transfer contribution of sliding bubbles within the overlapping region of bubble sliding trajectories.

\section{Acknowledgement}

This research was supported by CASL (Consortium for Advanced Simulation of Light Water Reactors), an Energy Innovation Hub under U.S. Department of Energy Contract No. DE-AC05-00OR22725. The support is gratefully acknowledged. 


\section{Reference}

[1] F.C. Gunther, Photographic study of surface-boiling heat transfer to water with forced convection, Trans ASME Ser CJ Heat Transf, 73 (1951) 115-123.

[2] K. Cornwell, The influence of bubbly flow on boiling from a tube in a bundle, International Journal of Heat and Mass Transfer, 33(12) (1990) 2579-2584.

[3] G. Thorncroft, J. Klausner, The influence of vapor bubble sliding on forced convection boiling heat transfer, ASME J. Heat Transfer, 121(1) (1999) 73-79.

[4] S. Houston, K. Cornwell, Heat transfer to sliding bubbles on a tube under evaporating and non-evaporating conditions, International journal of heat and mass transfer, 39(1) (1996) 211-214.

[5] N. Basu, G.R. Warrier, V.K. Dhir, Wall heat flux partitioning during subcooled flow boiling: Part 1—model development, Journal of heat Transfer, 127(2) (2005) 131-140.

[6] G. Yeoh, S.C. Cheung, J. Tu, M.K. Ho, Fundamental consideration of wall heat partition of vertical subcooled boiling flows, International Journal of Heat and Mass Transfer, 51(15) (2008) 3840-3853.

[7] L.A. Gilman, Development of a general purpose subgrid wall boiling model from improved physical understanding for use in computational fluid dynamics, Massachusetts Institute of Technology, 2014.

[8] N. Kurul, M. Podowski, On the modeling of multidimensional effects in boiling channels, in: Proceedings of the 27th national heat transfer conference, 1991, pp. 301-314.

[9] V.H. Delvalle, D.B.R. Kenning, Subcooled flow boiling at high heat-flux, Int J Heat Mass Tran, 28(10) (1985) 1907-1920.

[10] N. Zuber, The dynamics of vapor bubbles in nonuniform temperature fields, International Journal of Heat and Mass Transfer, 2(1-2) (1961) 83-98.

[11] R.L. Judd, K.S. Hwang, Comprehensive Model for Nucleate Pool Boiling Heat-Transfer Including Microlayer Evaporation, J Heat Trans-T Asme, 98(4) (1976) 623-629.

[12] B.-U. Bae, B.-J. Yun, H.-Y. Yoon, C.-H. Song, G.-C. Park, Analysis of subcooled boiling flow with one-group interfacial area transport equation and bubble lift-off model, Nucl Eng Des, 240(9) (2010) 2281-2294.

[13] B.-J. Yun, A. Splawski, S. Lo, C.-H. Song, Prediction of a subcooled boiling flow with advanced two-phase flow models, Nucl Eng Des, 253 (2012) 351-359.

[14] S. Maity, Effect of velocity and gravity on bubble dynamics, UCLA, 2000.

[15] R. Situ, T. Hibiki, M. Ishii, M. Mori, Bubble lift-off size in forced convective subcooled boiling flow, International Journal of Heat and Mass Transfer, 48(25-26) (2005) 5536-5548.

[16] J. Yoo, C.E. Estrada-Perez, Y.A. Hassan, Experimental study on bubble dynamics and wall heat transfer arising from a single nucleation site at subcooled flow boiling conditions-Part 1: Experimental methods and data quality verification, International Journal of Multiphase Flow, 84 (2016) 315-324.

[17] J. Yoo, C.E. Estrada-Perez, Y.A. Hassan, Experimental study on bubble dynamics and wall heat transfer arising from a single nucleation site at subcooled flow boiling conditions-Part 2: Data analysis on sliding bubble characteristics and associated wall heat transfer, International Journal of Multiphase Flow, 84 (2016) 292-314. [18] B.B. Mikic, W.M. Rohsenow, A New Correlation of Pool-Boiling Data Including Effect of Heating Surface Characteristics, Journal of Heat Transfer, 91(2) (1969) 245-250.

[19] D.B.R. Kenning, H. Victor, M. Delvalle, Fully-Developed Nucleate Boiling - Overlap of Areas of Influence and Interference between Bubble Sites, Int J Heat Mass Tran, 24(6) (1981) 1025-1032.

[20] J.G. Collier, J.R. Thome, Convective Boiling and Condensation, 3rd ed., Oxford University Press, United States, 1994.

[21] C.Y. Han, P. Griffith, The mechanism of heat transfer in nucleate pool boiling - Part II: the heat fluxtemperature difference relation International Journal of Heat Mass Transfer, 8 (1965) 905-914.

[22] S. Moghaddam, K. Kiger, Physical mechanisms of heat transfer during single bubble nucleate boiling of FC-72 under saturation conditions-II: Theoretical analysis (vol 52, pg 1295, 2009), Int J Heat Mass Tran, 52(25-26) (2009) 6061-6061.

[23] J. Kim, Review of nucleate pool boiling bubble heat transfer mechanisms, International Journal of Multiphase Flow, 35(12) (2009) 1067-1076.

[24] G. Thorncroft, J. Klausnera, R. Mei, An experimental investigation of bubble growth and detachment in vertical upflow and downflow boiling, International Journal of Heat and Mass Transfer, 41(23) (1998) 3857-3871.

[25] J. Yoo, C.E. Estrada-Perez, Y.A. Hassan, An accurate wall temperature measurement using infrared thermometry with enhanced two-phase flow visualization in a convective boiling system, International Journal of Thermal Sciences, 90 (2015) 248-266. 
[26] J. Yoo, C.E. Estrada-Perez, Y.A. Hassan, A proper observation and characterization of wall nucleation phenomena in a forced convective boiling system, International Journal of Heat and Mass Transfer, 76 (2014) 568584.

[27] N. Aybers, A. Tapucu, The motion of gas bubbles rising through stagnant liquid, Wärme-und Stoffübertragung, 2(2) (1969) 118-128.

[28] M. Wu, M. Gharib, Experimental studies on the shape and path of small air bubbles rising in clean water, Phys Fluids, 14(7) (2002) L49-L52. 